\title{
A Agrégation de Philosophie e a emergência do nietzschianismo filosófico francês*
}

\author{
Alan D. Schrift**
}

Resumo: Embora se acredite amplamente que a atenção francesa a Nietzsche nos anos 1960 era uma resposta à publicação das lições de Heidegger sobre Nietzsche em 1961, defendo que o aparecimento de Nietzsche na lista de leitura do exame de agrégation de philosophie fornece a melhor explicação para a emergência do chamado "New Nietzsche" em sua associação com o pós-estruturalismo francês. Após uma breve explicação de como a agrégation funciona na cultura acadêmica francesa e sua influência nas atividades docentes e publicações dos professores, analiso o aumento do interesse na obra de Nietzsche entre filósofos, desde o fim dos anos 1950, como consequência desse exame.

Palavras-chave: Nietzsche, agrégation de philosophie, pósestruturalismo, cultura acadêmica francesa, Deleuze, Bataille, Henri Lefebvre.

* Tradução: André Luís Mota Itaparica.

** Grinnell College, Grinnell, Iowa, Estados Unidos.

ORCID https://orcid.org/0000-0002-9413-6501

Correio eletrônico: schrift@grinnell.edu 
Schrift, A. D.

I

Quando filósofos anglófonos refletem sobre o interesse francês pelo pensamento de Nietzsche, eles o associam à imagem de um grupo de pensadores que se destacaram nos anos 1960 e que, fora da França, são agrupados sob a rubrica de "pós-estruturalismo". ${ }^{1}$ Mas o interesse francês por Nietzsche teve início quase um século antes: a quarta e última Consideração extemporânea foi a primeira de suas obras a ser traduzida, como Richard Wagner à Bayreuth, em janeiro de 1877, quase seis meses depois de o texto ter sido publicado em alemão. ${ }^{2} \mathrm{Na}$ época em que surgiram as primeiras obras de Nietzsche traduzidas para o inglês - Assim falava Zaratustra e $O$ caso Wagner foram publicados em inglês em 1896 - Henri Albert já tinha planejado uma tradução das obras completas de Nietzsche pela Mercure de France, finalizando seu projeto em 1909 com a tradução francesa do Ecce Homo. ${ }^{3}$ Esse entusiasmo inicial por Nietzsche foi alimentado pelo que podemos chamar das guerras culturais do fin de siècle francês, quando escritores associados tanto à esquerda vanguardista quanto à direita neomonarquista idealizaram Nietzsche como ícone cultural, do início dos 1890s até a Primeira Guerra Mundial. Uma segunda onda de interesse por Nietzsche na França teve lugar entre intelectuais não-conformistas, notadamente Georges Bataille, nos anos anteriores e posteriores à Segunda Guerra Mundial. Mas essa primeira atenção a Nietzsche na França ocupou, em grande medida, um espaço exterior à filosofia, e não deve omitir o fato de que a associação de nietzschianismo e filosofia na França, após o pós-estruturalismo, não está equivocada, porque ela não existia até que os filósofos franceses, no final dos anos 1950, se engajaram na obra de Nietzsche como filosofia. Contudo, antes de observar a

1 Boa parte desta discussão introdutória foi extraída de meu ensaio "French Nietzscheanism” (Schrift, 2010, pp. 19-46).

2 Richard Wagner in Bayreuth foi publicada em julho de 1876 pela editora Ernst Schmeitzner. Schmeitzner também publicou Richard Wagner à Bayreuth, traduzido para o francês por Marie Baumgartner.

3 Pinto sugere que esses planos tinham sido pensados já em 1894 (Pinto, 1998, p. 25n).

118 | Cad. Nietzsche, Guarulhos/Porto Seguro, v.41, n.2, p. 117-144, maio/agosto, 2020. 
emergência desse momento filosófico singular do nietzschianismo francês, é necessário fazer breves comentários sobre dois momentos.

No final do século XIX e no início do XX, havia, na França, um interesse considerável no pensamento de Nietzsche, mas ele estava localizado sobretudo fora da universidade, e, quando na universidade, estava fora da faculdade de filosofia. ${ }^{4}$ Em 1902-1903, um curso de um ano foi dedicado a Nietzsche na Sorbonne, no departamento de língua alemã, ministrado por Henri Lichtenberger (1864-1941), cujo livro, La Philosophie de Nietzsche, ${ }^{5}$ incialmente publicado em 1898, já estava em sua nona impressão em 1905. Charles Andler (1866 - 1933), também professor de literatura alemã, publicou um estudo sobre Nietzsche em seis volumes, entre 1920 e 1931. ${ }^{6}$ Fora da universidade, dos anos 1890 ao início do século XX, Nietzsche era amplamente lido pela vanguarda e a ela associado, particularmente André Gide (1869-1951) e seu círculo, muitos dos quais estudaram com Andler na École Normale Supérieure e posteriormente se associarram à $L a$ Nouvelle revue française. Havia uma atração por Nietzsche entre certos círculos literários e políticos associados com a direita. No início dos anos 1890, e depois filiada a Charles Maurras (1868-1952) e à Action Française, a atração da direita por Nietzsche continuou até a aproximação da Primeira Guerra, quando suas posturas nacionalistas e antigermânicas tornaram impossível para eles o apelo a Nietzsche. ${ }^{7}$ Enquanto a esquerda literária recebia Nietzsche como um poeta-filósofo que desafiou

\footnotetext{
4 Verbaere (1999) nota que entre 1890 e 1910, mais que 1.100 referências a Nietzsche apareceram na França, com 47 livros e mais de 600 artigos ou estudos discutindo seu pensamento (Apud: Le Rider, 1999, p. 104).

5 Lichtenberger, 1898.

6 Les Précurseurs de Nietzsche (1920); La Jeunesse de Nietzsche: Jusqu'à la rupture avec Bayreuth (1921); Le Pessimisme esthétique de Nietzsche: Sa philosophie à l'époque wagnérienne (1921); La Maturité de Nietzsche: Jusqu'à sa mort (1928); Nietzsche et le transformisme intellectualiste: La Philosophie de sa période française (1922); La Dernière philosophie de Nietzsche: Le Renouvellement de toutes les valeurs (1931). Os dois primeiros volumes de Andler foram enviados à editora Félix Alcan em 1913, mas sua publicação naquela época não foi possível, por causa da guerra (Cf. Le Rider, 1999, p. 84). Os seis volumes foram publicados juntos, em três volumes, pela Gallimard, em 1958, como Nietzsche, sa vie et sa pensée.

7 Para uma discussão sobre a atração literária de Nietzsche pela direita e pela esquerda nesse período, ver: Forth (2001); para uma discussão da apropriação de Nietzsche pela Action Française, ver: Virtanen,1950.
} 
os limites da moralidade contemporânea, o establishment filosófico desdenhava das transgressões estilísticas de Nietzsche, que eles atribuíam a seu "irracionalismo" e "imoralismo". Enquanto Gide divulgava sua associação com Nietzsche em seu L'Immoraliste, publicado em 1902, o livro Nietzsche et l'immoralisme, ${ }^{8}$ de Alfred Fouillée, uma das pouquíssimas obras escritas por um filósofo nesse período, também apareceu em 1902, e era extremamente crítica a Nietzsche, questionando por que algum filósofo sério se ocuparia com seu pensamento. De fato, Nietzsche era tão intimamente identificado com o "imoralismo" que o termo foi introduzido e definido como "a doutrina de Nietzsche" no prestigioso dicionário filosófico Vocabulaire technique et critique de la philosophie, compilado, de 1902 a 1923 , por membros da Société Française de Philosophie, sob a direção de seu secretário geral André Lalande. ${ }^{9}$

A quase total incapacidade de filósofos universitários de reconhecer a obra de Nietzsche, dos anos 1890 até a Primeira Guerra Mundial e depois, é menos o resultado de pouca familiaridade com sua obra e mais uma consequência do desejo de "profissionalizar" a filosofia, ao enfatizar o rigor lógico e científico e ao distinguir claramente filosofia e literatura. ${ }^{10}$ Durante esse período, embora houvesse antagonismos significativos entre as três "escolas" dominantes no interior da filosofia acadêmica francesa - os positivistas, os neokantianos e os espiritualistas - os professores universitários estavam unidos na ideia de que a universidade era lugar apenas para discussão filosófica "séria". Como consequência, a popularidade de Nietzsche entre os assim chamados filósofos "amadores" era tomada

8 Fouillée, 1902.

9 Os membros da Société se encontravam regularmente para discutir o significado de conceitos-chave da terminologia filosófica, e publicavam seus anais em duas edições anuais do Bulletin de la Société Française de Philosophie. Lalande coligiu e comentou esses anais e os publicou na editora Félix Alcan em um único volume em 1925-26. A décima oitava edição do Vocabulaire foi publicada pela Presses Universitaires de France, em 1996.

10 Pinto faz essa observação (Pinto, 1998, p. 38). Pode-se relacionar a hostilidade dos filósofos acadêmicos a Nietzsche com a animosidade similar dos filósofos da Sorbonne e da École Normale Supérieure em relação à obra de Henri Bergson.

120 | Cad. Nietzsche, Guarulhos/Porto Seguro, v.41, n.2, p. 117-144, maio/agosto, 2020. 
A Agrégation de Philosophie e a emergência do nietzschianismo...

como evidência de seu pouco valor filosófico no interior da academia. ${ }^{11}$ Mesmo depois da Primeira Guerra Mundial, Nietzsche permaneceu um figura canônica nos estudos germânicos, como evidenciado pelo fato de que, no início de 1903, Nietzsche aparece aproximadamente a cada quatro ou cinco anos no Programme da Agrégation d'allemand, até mesmo durante a Segunda Guerra Mundial, quando ele aparece nos Programmes em 1940 e 1942. E enquanto Nietzsche permaneceu sobretudo como parte do debate cultural entre direita e esquerda, quase não havia pesquisa filosófica sobre seu pensamento.

Dos anos 1930 aos 1950, Nietzsche continuou a ser ignorado pelos filósofos universitários. Por exemplo, quando Armand Quinot e Geneviève Bianquis fundaram a Société Française d'Etudes Nietzschéennes, em 1946, ${ }^{12}$ seus oito fundadores eram todos germanistas, com exceção do filósofo Félicien Challaye, cuja carreira consistiu no ensino em vários liceus parisienses (Louis-le-Grand, Janson-de Sailly, Charlemagne, Condorcet). Mas, nesses anos, um "segundo momento" do nietzschianismo francês tomou corpo quando seu pensamento surgiu como uma importante referência para teóricos vanguardistas que, nos anos 1960, se associaram a filósofos. A figura mais importante foi Georges Bataille, para quem Nietzsche era um constante objeto de reflexão, da fundação da revista Acéphale, em 1936, até o seu Sur Nietzsche, publicado em 1945. ${ }^{13}$ Por meio de Bataille, Pierre Klossowski e outros, incluindo o filósofo Jean Wahl, Nietzsche era uma presença constante nas atividades do Collège de Sociologie. Duas características distinguem o trato de Bataille com Nietzsche: sua tentativa de ler Nietzsche em relação a Hegel e seu desejo de desafiar a associação do pensamento de Nietzsche com o fascismo e o nacional-socialismo. Essas características se

110 aspecto geral da hostilidade entre filósofos "profissionais" (isto é, acadêmicos) e os filósofos "amadores" é discutido em Fabiani, 1985, pp. 377-409, em particular pp. 382-85.

12 A sociedade continuou até 1965 e depois incluiu, entre seus membros, Jean Wahl, Angèle Kremer-Marietti, Gilles Deleuze, Richard Roos, Pierre Boudot e Jacques Derrida.

13 Bataille, 1945.

Cad. Nietzsche, Guarulhos/Porto Seguro, v.41, n.2, p. 117-144, maio/agosto, 2020.| 121 
Schrift, A. D.

uniram na idealização de Bataille de Nietzsche como "o herói de tudo que é humano que não é escravizado". ${ }^{14}$ Desenvolvendo essas características, Bataille enfatiza, mais que as leituras francesas anteriores, o lugar do eterno retorno no pensamento de Nietzsche. Bataille e seus colaboradores na Acéphale foram todos influenciados pelo livro Nietzsches Philosophie der ewigen Wiederkehr des Gleichens, de Karl Löwith, publicado em 1935 e resenhado por Klossowski no segundo número da Acéphale (Janeiro de 1937), que foi dedicada inteiramente a Nietzsche e intitulada "Réparation à Nietzsche."15 Para Bataille, enquanto a filosofia de Hegel é conduzida por uma teleologia inabalável, o pensamento de Nietzsche do eterno retorno afirma a imanência de cada momento como um fim imotivado por si mesmo. E enquanto a dialética da negação determinada de Hegel não deixa nada para o acaso, a ênfase de Nietzsche na morte de Deus e nas possibilidades imanentes, excessivas do momento, deixa tudo para o acaso. Considerando a vontade de acaso como o núcleo do eterno retorno, Bataille retira a ênfase da vontade de potência, que ele considerava como central na apropriação, deliberada e equivocada, do pensamento de Nietzsche. Ele também criticava a valorização fascista da vontade de potência por ser motivada por uma racionalidade instrumental que reduzia todos os valores a valor de uso, ao invés de afirmar a transvaloração de todos os valores, que abre o futuro à possibilidade do novo.

Outra obra significativa sobre Nietzsche escrita nesse período foi escrita pelo sociólogo Henri Lefebvre e intitulada simplesmente Nietzsche. Como Bataille, Lefebvre quer ler Nietzsche contra os fascistas, argumentando que

A ideia nietzschiana do futuro não é fascista. "Supere! Ultrapasse!". Esse imperativo nietzschiano é precisamente o contrário do postulado fascista,

14 Bataille, 1985, p. 203.

150 segundo número de Acéphale também incluía o importante ensaio de Bataille "Nietzsche et les fascistes."

122 | Cad. Nietzsche, Guarulhos/Porto Seguro, v.41, n.2, p. 117-144, maio/agosto, 2020. 
A Agrégation de Philosophie e a emergência do nietzschianismo...

segundo o qual os conflitos são eternos e os problemas humanos não têm solução. ${ }^{16}$

Diferentemente de Bataille, contudo, Lefebvre também procurou enfatizar tanto o existencialismo de Nietzsche quanto sua compatibilidade com Marx. Lefebvre, um marxista convicto e membro do partido comunista francês (até ser expulso em 1958), abre seu texto com uma epígrafe dos manuscritos de 1844 de Marx e prossegue argumentando que a atenção de Nietzsche à alienação humana levanta temas importantes que são largamente ignorados na consideração exclusivamente econômica de Marx. Ao mesmo tempo, ele afirma que Nietzsche não possui uma teoria coerente da alienação, o que requereria que ele visse a alienação do pensamento da vida "como resultado da diferença social e da divisão do trabalho" (p.144). A visão marxista de Lefebvre se dirige ao existencialismo quando ele nota que, no futuro magnificente de Nietzsche, "os homens de nossa época desejam, sofrem, se desesperam e sempre retornam a se esperançar. E é isto que confere à sua vida seu caráter único" (p. 164). Por Lefebvre achar fácil integrar a transvaloração dos valores de Nietzsche "com o conceito marxista de homem", até mesmo o eterno retorno se ajusta à visão de futuro, marxista e existencialista, de Lefebvre, já que o eterno retorno promove o surgimento do imperativo nietzschiano, "um imperativo que dota a existência de uma densidade infinita: 'viva cada momento de uma forma que você queira revivêlo eternamente' ['Vis tout instant de sorte que tu veuilles toujours le revivre']. Não existe uma verdade eterna e pré-existente que nos determinaria fatalmente. Ao contrário: nós criamos a eternidade, nossa eternidade!" (p. 87).

Em contraste com os dois momentos anteriores, o que distingue o terceiro momento nietzschiano na França é precisamente que o pensamento de Nietzsche é, pela primeira vez, aceito por filósofos

16 Lefebvre, 1939, p. 162. 
profissionais. E é aqui que que eu gostaria de chamar atenção para a agrégation de philosophie e seu impacto e influência na filosofia na França. Para isso, permitam-me desviar de Nietzsche um pouco e falar, de forma mais geral, sobre a agrégation. Mas, antes, vou contextualizar as observações que se seguem relembrando duas anedotas que inicialmente me fizeram ter interesse pela agrégation de philosophie, porque enquanto qualquer filósofo francês está bem ciente da importância da agrégation, a maioria de filósofos e estudantes de filosofia fora da França provavelmente nunca ouviu falar da agrégation de philosophie.

Enquanto fazia uma pesquisa para um livro sobre a história da filosofia na França no século XX, eu cruzei com nomes de filósofos como Jean Wahl, Maurice de Gandillac e Ferdinand Alquié, que eram claramente influentes no desenvolvimento daquela história, mas que eram largamente desconhecidos no mundo filosófico anglófono. Por isso, eu decidi acompanhar minha narrativa da história com breves biografias de muitas dessas figuras, cujos nomes apareciam e cujas obras poderiam nunca ter sido traduzidas para o inglês, mas cujos nomes apareciam com frequência nas dedicatórias de livros escritos por filósofos muito mais conhecidos nos Estados Unidos, como Deleuze ou Derrida. Isso me levou a examinar muitas histórias e antologias da filosofia francesa do início do século XX, assim como outros lugares onde informações biográficas podem ser encontradas, como no Who's Who in France ou nos obituários publicados no anuário da associação de alunos da École Normale Supérieure. Para mim, ficou rapidamente claro o formato dessas breves notas biográficas: sempre começavam com o nome, seguido, entre parênteses, das datas de nascimento e morte, e a cidade ou região onde o filósofo nasceu. A segunda frase era quase sempre a mesma: onde eles frequentaram a universidade (comumente a École Normale) e em que ano eles passaram na agrégation, incluindo sua posição, caso tenha sido primeiro ou segundo lugar. Então vinham informações 
A Agrégation de Philosophie e a emergência do nietzschianismo...

sobre seu doctorat, carreira docente, livros importantes escritos e outros detalhes específicos. Embora eu considerasse conhecer razoavelmente as instituições acadêmicas francesas, eu nunca tinha ouvido falar de agrégation e não tinha a menor ideia do que havia de tão importante na agrégation de philosophie para ela ser listada numa nota biográfica antes do doctorat ou dos livros publicados ou dos liceus ou universidades nos quais o filósofo passou em sua carreira.

Uma segunda anedota diz mais diretamente sobre o que discutirei quando retornar a Nietzsche. Eu comecei a passar um tempo em Paris todos os verões no início dos anos 1990, e um dos meus ritos anuais era visitar a loja da livraria Vrin, para saber o que estava acontecendo no momento na filosofia francesa. Numa licença sabática em Paris, no inverno de 2000, quando eu parei na Vrin e olhei para o painel onde listava os livros recentemente publicados, eu vi seis ou sete novos livros sobre Plotino. Não me lembrava de ter visto um livro recente sobre Plotino, seja na França ou nos Estados Unidos, e fiquei tão surpreso que chamei a vendedora e perguntei por que havia tantos livros sobre Plotino. Ela sorriu e disse simplesmente "C'est l'agrégation." O que é essa agrégation?, imaginei na época, e minha curiosidade só cresceu quando uma pesquisa posterior me levou a descobrir que Plotino apareceu seis vezes na lista de leitura para a agrégation nos anos 1990, e, doze anos depois de seu aparecimento inicial em 1991, o número de livros publicados sobre seu pensamento na França era quase uma vez e meia vezes maior do que o número do que havia sido publicado nas nove décadas anteriores. ${ }^{17}$ Assim começou minha fascinação com a agrégation de philosophie, da qual apresentarei alguns resultados.

17 Trinta e um livros apareceram entre 1991 e 2003, enquanto vinte e três livros haviam aparecido entre 1900 e 1990. Desconheço aqui a história das edições subsequentes das obras publicadas antes, já que essas não refletem pesquisa nova. 
Schrift, A. D.

II

Primeiro, deixe-me começar com um pouco de história. A agrégation foi criada em 1766 pelo estado francês como um certame para habilitar professores do ensino médio. A agrégation original era um exame único, que procurava habilitar professores em três áreas: gramática, letras e filosofia. ${ }^{18}$ Sua criação, no entanto, teve implicações políticas importantes, especialmente para o ensino da filosofia, na medida em que retirou a prerrogativa de habilitar esses professores das mãos de uma comissão examinadora selecionada pela Faculdade de Teologia da Sorbonne e, em vez disso, transferiu essa prerrogativa a uma comissão sob o controle exclusivo da Faculdade de Artes. A Faculdade de Artes abrigava as faculdades de humanidades e de ciências e, desde a fundação da Universidade de Paris, no século XII, foi considerada uma faculdade "inferior" em comparação às três faculdades "superiores" de Teologia, Direito e Medicina. Podem-se lembrar aqui as Meditações de Primeira Filosofia, de Descartes, que começam com um apelo, "aos homens mais instruídos e distintos, o Diretor e os doutores da sagrada Faculdade de Teologia de Paris", para que eles tomassem seu trabalho sob sua proteção. Essa solicitação não foi só consequência da preocupação de Descartes de que seu trabalho pudesse ser considerado herético; também foi um cálculo político de Descartes, baseado na relativa fraqueza da Faculdade de Artes da Sorbonne em relação à Faculdade de Teologia.

O lugar privilegiado da filosofia nesse exame único foi, desde o início, objeto de disputa política, já que tanto a Faculdade de Artes da Sorbonne, que representava os interesses laicos do Estado, quanto a faculdade de teologia procuravam controlar a comissão que avaliava o componente de filosofia. Isso levou à primeira revisão significativa da agrégation, em 1821, quando o exame único de agrégation foi dividido em três certames distintos, um de ciência,

18 Chervel, 1993, p. 18. A maioria dos próximos detalhes a respeito da história do início da agrégation provém desta obra.

126 | Cad. Nietzsche, Guarulhos/Porto Seguro, v.41, n.2, p. 117-144, maio/agosto, 2020. 
um de letras (que incluía a filosofia) e um de gramática. Quatro anos depois, a agrégation de lettres se dividiu em duas - uma agrégation de lettres e uma agrégation de philosophie - sendo a última criada especificamente para habilitar professores para ministrar aulas de filosofia, ${ }^{19}$ e motivada politicamente pelo desejo de colocar o exame novamente sob o controle da faculdade de teologia da Sorbonne, como parte do esforço de restabelecer o poder da Igreja Católica Romana na França, depois da queda de Napoleão. Esse esforço foi em grande medida exitoso e, por volta do fim da restauração, em 1830, mais da metade dos professores de filosofia na França eram membros do clero. ${ }^{20}$ Mas as coisas mudaram novamente com o estabelecimento de uma monarquia constitucional em julho de 1830, quando o filósofo Victor Cousin (1792-1867) foi indicado como presidente do jury d'agrégation e a língua para as dissertações escritas passou do latim para o francês. Com essas mudanças, a agrégation de philosophie se tornou verdadeiramente um exame de filosofia independente, libertando-se completamente da autoridade da faculdade de teologia. ${ }^{21}$

Em sua forma moderna, a agrégation é um certame (chamado Concours) que habilita estudantes para o ensino de filosofia no ensino médio e posterior. $\mathrm{O}$ conteúdo do exame é escolhido por um jury d'agrégation, que trabalha sob os auspícios do Ministério da Educação, tendo como base o Programme de filosofia definido no ano anterior. A estrutura e o conteúdo da agrégation de filosofia foi objeto de debate e discussão quase constante no decorrer do século

19 Na resolução de 12 de julho de 1825 .

20 Chervel, 1993, p. 79.

21 Na resolução de 11 de setembro de 1830. Nos anos subsequentes, muitos outros exames de agrégation foram também criados, incluindo exames de história e geografia (1831), matemática (1841), alemão (1849) e inglês (1849). 
$\mathrm{XX} .^{22}$ Nos primeiros anos do século XX, o exame consistia de duas partes: um exame escrito preliminar e um exame oral final. ${ }^{23}$ A parte escrita consistia de três dissertações, sendo reservadas sete horas para cada uma delas, com frequência agendadas na mesma semana, com duas questões de filosofia geral e uma de história da filosofia. Após o exame escrito, do qual normalmente apenas um em cada quatro candidatos passava, vários exames orais eram requeridos. Enquanto o objetivo do exame escrito era se certificar dos conhecimentos e das habilidades filosóficas do candidato, a meta do exame oral era verificar os talentos pedagógicos do candidato. No primeiro exame oral, eram dados ao candidato três textos filosóficos para que ele preparasse uma explicação oral de trinta minutos. $\mathrm{O}$ segundo exame oral exigia que o candidato apresentasse uma "aula" de um assunto determinado, para cuja preparação ele teria seis horas de acesso à biblioteca da Sorbonne. No fim das contas, o número de candidatos que passava na agrégation era determinado pelo Estado, de acordo com o número de vagas para professor disponíveis. Os resultados da agrégation de1913 são típicos dessa época passada: de sessenta e seis estudantes que se inscreveram no exame, dezessete passaram no exame escrito e estavam habilitados para o exame oral; destes, no fim sete foram admitidos como agrégés.

\footnotetext{
22 Para uma discussão fascinante da agrégation de filosofia, ver os anais de 7 de maio de 1938 do encontro da Société Française de Philosophie, que foi dedicada a esse assunto: "L'Agrégation de philosophie", Bulletin de la Société Française de Philosophie, vol. 38, 1938, pp. 117-58. Nessa discussão, veem-se muitos problemas perenes levantados: questões a respeito do estresse provocado por um exame tão rigoroso, o problema da "lacuna geracional" entre examinadores e estudantes, a relativa importância de demonstrar conhecimento técnico em relação à capacidade pedagógica, a importância de conhecer o cânon filosófico, etc. Outra questão que emerge nessa discussão dirige-se diretamente às tensões entre a Sorbonne e a École Normale Supérieure. Esta questão diz respeito se a agrégation, cujo objetivo é identificar bons professores que conhecem a matéria que lhes é exigida para ensinar, preteria o filosofar criativo. Enquanto o establishment da Sorbonne (Léon Brunschvicg, Désiré Roustan e Dominique Parodi) questionava se a École Normale estava focada o bastante para garantir que seus estudantes conheceriam a matéria, os representantes da ENS, Célestin Bouglé (seu diretor), e Maurice MerleauPonty, o agrégé-répétiteur, sugerem que, na medida em que a ENS encoraja a independência do pensamento, seus estudantes poderiam ser preteridos em relação a avaliadores mais conservadores da Sorbonne. Bouglé, em particular, fica bastante na defensiva, sugerindo, em certo momento, que a sessão deveria ter o subtítulo "como explicar o fracasso dos normaliens na agrégation" (p. 138).
}

23 Esta era basicamente a forma que o exame tomou quando foi inicialmente criado. 
A Agrégation de Philosophie e a emergência do nietzschianismo...

Uma taxa de aprovação de aproximadamente dez por cento de candidatos da agrégation é típica desses anos, e a taxa de reprovação não aumentou desde então. Por exemplo, apenas vinte e um candidatos passaram, de 343 inscritos no exame em 1951 (6.1\%), e, mais recentemente (2018), um pouco menos que cinco por cento $(61=4.8 \%)$ de um total de 1270 candidatos que se inscreveram acabaram passando na agrégation. Entre filósofos famosos que não passaram na agrégation de primeira, encontram-se Jean-Paul Sartre, Jean Beaufret, Michel Foucault e Jacques Derrida. O caso de Sartre, que foi um escândalo, já que ele era visto por muitos como o melhor estudante de filosofia da École Normale, dá ensejo a ver alguns dos problemas da forma de avaliação do exame. Em 1928, Sartre recebeu a menor nota entre os cinquenta que fizeram o exame, mas seu então amigo, Raymond Aron, que recebeu a maior nota naquele ano, afirmou que Sartre não passou porque ele aproveitou a oportunidade para apresentar algumas de suas próprias ideias sobre a natureza da existência. ${ }^{24} \mathrm{O}$ próprio Sartre, interrogado anos depois sobre o seu fracasso na agrégation, respondeu: "Tentei ser original nas minhas redações filosóficas. Isso desagradou e recebi as piores notas. No ano seguinte eu entendi: devia-se produzir uma cópia banal, apresentando-a de maneira original". ${ }^{25}$ No ano seguinte, Sartre passou na agrégation, dessa vez com as maiores notas, seguido de Simone de Beauvoir e Jean Hyppolite em terceiro.

Enquanto o fracasso inicial de Sartre atesta o conservadorismo inerente à agrégation, deixem-me observar aqui outro escândalo na história da agrégation de philosophie, escândalo esse que pode muito bem ter alterado a recepção de Nietzsche entre filósofos na França. Nesse caso, ele pouco tinha a ver com conservadorismo, mas com o abuso de poder por parte de membros da comissão de avaliação, como veremos no caso notório de Charles Andler, o professor de

24 Aron, 1990, p. 25.

25 Sartre, 1981, p. xlv.

Cad. Nietzsche, Guarulhos/Porto Seguro, v.41, n.2, p. 117-144, maio/agosto, 2020. | 129 
Schrift, A. D.

literatura alemã que mencionei anteriormente, que deixou de passar na agrégation de philosophie em 1887 e 1888 quase exclusivamente por culpa do influente idealista neokantiano Jules Lachelier. Durante os anos 1880, a comissão era particularmente hostil às concepções metafísicas de Émile Boutroux e suas críticas a algumas doutrinas tradicionais, e Lachelier, em particular, era extremamente rigoroso com os estudantes de Boutroux provenientes da École Normale, que se referiam a ele como "o tirano do exame". Andler, que estudou com Boutroux na École Normale, em 1887 passou no exame escrito muito bem classificado, mas um membro da banca ligado a Lachelier (Elie Rabier) lhe deu nota zero no exame oral, e, embora os outros membros lhe tenham dado notas boas, esse zero impossibilitou que ele passasse. ${ }^{26}$ No ano seguinte, Lachelier leu pessoalmente as redações de Andler, que não passou sequer no exame escrito, sendo que a opinião de Lachelier sobre as dissertações de Andler estavam, como André Canivez escreveu, "em termos tão definitivos que Andler entendeu que seria inútil se apresentar mais uma vez" ${ }^{27}$ Andler mudou de área, passou com sucesso na agrégation d'allemand em 1889, obtendo o primeiro lugar, e prosseguiu numa carreira admirável na área da literatura alemã, primeiro na École Normale, depois na Sorbonne, e finalmente no Collège de France (1926-33), publicando um número de obras importantes, incluindo seu estudo em seis volumes sobre Nietzsche. Pode-se apenas imaginar qual seria o destino filosófico de Nietzsche na França caso Andler tivesse sido membro da faculdade de filosofia e não da de letras e literatura alemãs.

Uma última questão histórica: desde 1950, passar na agrégation não é mais necessário para ensinar no ensino médio, já que outro exame - o CAPES (Certificat d'Aptitude au Professorat de l'Enseignement Secondaire) - foi criado para preencher a necessidade

26 Ver: Tonnelat, 1937, pp. 31-32.

27 Ver: Canivez,1994, pp. 199-200.

130 | Cad. Nietzsche, Guarulhos/Porto Seguro, v.41, n.2, p. 117-144, maio/agosto, 2020. 
A Agrégation de Philosophie e a emergência do nietzschianismo...

de mais professores do ensino médio sem diminuir o prestígio da agrégation. Ensinar numa universidade num cargo acima do de assistente, no entanto, ainda exige a aprovação na agrégation, que permanece como uma marca de distinção, já que aqueles que são aprovados gozam de alguns privilégios, como maiores salários e menores cargas horárias.

\section{III}

Fiquei interessado na agrégation porque penso que ela teve um enorme impacto nos desenvolvimentos na filosofia francesa. A razão disso é que figuras que aparecem no Programme englobam, em sua maior parte, figuras canônicas da história da filosofia, com relativamente poucas figuras do século XIX e menos ainda do século XX. Quando um texto filosófico aparece no Programme para o exame oral da agrégation, isso significa que todos os estudantes que, naquele ano, tenham esperança de uma carreira na filosofia, passarão o ano estudando aquele texto intensivamente. Ainda mais significativo, até isso ser mudado em 2005, quando um filósofo era indicado no Programme para o exame escrito, isso significava, assim era esperado, que o estudante conhecesse por inteiro a obra do filósofo. Não é de admirar que dedicar um ano, às vezes dois, concentrado numa figura, tem como resultado não apenas publicações posteriores sobre aquela figura, mas também que aquela figura se torne, com frequência, uma fonte intelectual constante para uma carreira posterior.

Contudo, o impacto da agrégation não está restrito aos estudantes. Há outro efeito que pode ser mais significativo, qual seja, o efeito que o Programme anual tem sobre as atividades docentes. Há a expectativa de que os temas de muitos cursos universitários serão escolhidos de acordo com temas anunciados ou antecipados para os próximos exames. Por exemplo, se compararmos o que constava no Programme 
para a agrégation de philosophie de $1939^{28}$ com o que era ensinado na faculdade de filosofia da Sorbonne durante o ano acadêmico, a correlação é significativa. As obrigações típicas de ensino de um professor da Sorbonne consistiam em ministrar um curso e oferecer uma conférence semanal. ${ }^{29}$ Dos oito cursos de filosofia ministrados durante o ano acadêmico de 1938-39, quatro são sobre figuras que apareceram no Programme. ${ }^{30} \mathrm{E}$ de dez conférences, oito se relacionam diretamente com a agrégation. ${ }^{31}$ Somente um membro da faculdade de filosofia $^{32}$ não lista uma atividade de ensino relacionada ao conteúdo da aggregation daquele ano, e quase três quartos das atividades docentes da faculdade de filosofia da Sorbonne se relacionam claramente com a preparação de seus estudantes para o exame.

Posteriormente, no século XX, dedicar-se à agrégation se tornou parte das obrigações docentes "exigidas" da faculdade de filosofia, em particular nas faculdades com cadeiras em história da filosofia, como se pode ver ao verificar o ano acadêmico de 1963-64. Nesse ano, a faculdade de filosofia da Sorbonne possuía treze cadeiras, quatro delas em história da filosofia. ${ }^{33}$ Quando se compara o Programme

28 O Programme para a agrégation de philosophie em 1939 listou Platão, Descartes, Malebranche e Kant como autores para a composição escrita sobre a história da filosofia, e listou para explicação no exame oral textos gregos de Platão (Phédon [Fédon]) e Aristóteles (Physique), texto em latim de Spinoza (Ethica, IV) e Leibniz (Méditationes de cognitione, veritate et ideis, De rerum originatione radicali e De primae philosophiae emendatione et de notione substantiae), textos em francês de Berkeley (Dialogues entre Hylas et Philonous) e Ravaisson (De l'habitude), e para candidatos que poderiam renunciar à explicação de grego, textos em inglês de Mill (An Examination of Sir William Hamilton's Philosophy, chap. II-VII) e James (A Pluralistic Universe) ou textos em alemão de Kant (Kritik der Urtheilskraft, Deuxième Partie: Critique du jugement téléologique) e Schelling (Bruno).

29 Uma conférence é um curso com inscrição normalmente restrita a candidatos para a agrégation, a licence ou habilitação numa disciplina específica (por exemplo, história e filosofia da ciência).

30 "La Philosophie de Descartes", de Albert Rivaud, "La Monde intelligible dans le néoplatonisme" e "Questions d'histoire de la philosophie grecque", de Émile Bréhier e "Le Rationalisme de Malebranche", de Jean Laporte.

31 "Textes de Spinoza (Ethique livre IV) et de Leibniz," de Rivaud, "Explication de la Physique d'Aristote", de Jean Wahl, "Préparation à l'Agrégation", de Léon Brunschvicg, "Auteurs du programme”, de Charles Lalo. A conférence do primeiro semestre de Laporte, "Philosophie générale", e do Segundo semestre, "Histoire de la philosophie", "Agrégation", de Maurice Halbwachs, junto com "La Perception de l'espace", da cadeira de psicologia de René Poirier's

32 Abel Rey, titular da cadeira de História e Filosofia da Ciência.

33 As cadeiras de história da filosofia pertenciam a Maxime Schuhl, Maurice de Gandillac, Henri Gouhier, Ferdinand Alquié e Guitton.

132 | Cad. Nietzsche, Guarulhos/Porto Seguro, v.41, n.2, p. 117-144, maio/agosto, 2020. 
para a agrégation ${ }^{34}$ de 1964 com os cursos oferecido nas cadeiras de história da filosofia para o ano acadêmico, a questão é clara: quatro delas ofereciam cursos intitulados especificamente "Agrégation," e dos oito cursos que os historiadores da filosofia ofereciam, todos eram dedicados a figuras listadas para ao exame escrito ou a um texto específico do exame oral. ${ }^{35}$

$\mathrm{O}$ que esses dados indicam é que não somente o trabalho de estudantes avançados, mas mais ainda a obra dos professores, foram determinados em resposta ao Programme da agrégation e, é obvio, há um vínculo direto entre o que os professores estão ensinando e suas publicações posteriores. Por exemplo, durante os três anos em que Deleuze ensinou como Maître-assistant em História da filosofia na Sorbonne, estavam incluídos, entre os filósofos dos Programmes para o exame escrito ou explicação em francês, Bergson, Kant e os estoicos (em 1957), e Spinoza, Hume, Kant e Nietzsche (em 1958 e 1959). Embora o livro de Deleuze sobre Hume tenha aparecido antes (em 1953), ele publicou sobre todas essas outras figuras na década seguinte a seus anos de ensino na Sorbonne. Um segundo exemplo foi relatado para mim por um antigo estudante de Derrida na École Normale. Quando o livro La Vérité en peinture ${ }^{36}$, de Derrida, foi publicado em 1978, um antigo estudante contou que, ao comparar o texto de Derrida com suas próprias anotações do seminário de Derrida em 1974, ele achou os dois substancialmente iguais. Mas isso não

34 O Programme para a agrégation de 1964 listava os estoicos e epicurianos e Kant, como tema para a redação histórica, e inclui, entre os textos para o exame oral, Lettre sur les aveugles, de Diderot, Critique de la raison pure (Dialectique transcendentale, livre II, chapitre II: Antinomie de la raison pure), de Kant, Lettres à Lucilius (lettres 71, 72, 73, 74, 82, et 88), de Séneca, Regulae, de Descartes, Théétète, de Platão, Des parties des Animaux, (livre I [entire] et II [selections]), de Aristóteles, Kritik der Urteilskraft (Vorrede, Einleitung, Erster Teil), de Kant.

35 Schuhl oferece "La Matière chez les premiers penseurs grecs" no primeiro semestre, e "Textes latins. Textes grecs", no segundo semestre, Gandillac oferece "Explication d'Aristote: Des parties des Animaux", no primeiro semestre, e "Explication de Sénèque, Lettres à Lucilius", no segundo, Gouhier ministra um curso de dois semestres sobre "Diderot, Lettre sur les aveugles," e Alquié ministra curso de dois semestres sobre "La Philosophie de Kant." Além disso, Schuhl oferece um seminário de pesquisa sobre Aristóteles e Alquié oferece um seminário de pesquisa sobre Descartes. Os cursos de Guitton não estão na lista daquele ano; também ele pôde ter ministrado um curso preparatório para a agrégation.

36 Derrida, 1978.

Cad. Nietzsche, Guarulhos/Porto Seguro, v.41, n.2, p. 117-144, maio/agosto, 2020. | 133 
surpreende, quando se sabe que Kant foi uma das figuras listadas no Programme para a redação histórica e que o tema da segunda redação daquele ano foi "L'art." 37 Dado o impacto do aparecimento de um filósofo no Programme em todo âmbito acadêmico da filosofia - em termos de ensino, pesquisa e publicações -, é portanto importante quem participava da comissão que selecionava as figuras que apareceriam no Programme, e igualmente importante que figuras aparecem frequentemente ou regularmente no Programme e quais não. Analisar o conteúdo dos Programmes, assim, reflete o conhecimento fundacional histórico que filósofos educados na França utilizarão, frequentemente sobre o qual escreverão, no início e, às vezes, por toda sua carreira.

\section{IV}

Voltando agora brevemente ao conteúdo do exame, desde o início do século XX e continuando no presente, o exame enfatizou a história da filosofia e sempre privilegiou filósofos antigos canônicos e os primeiros modernos na parte escrita do exame, com um dos três exames escritos se focando especificamente num tópico na história da filosofia. Isso é digno de nota porque as figuras que aparecem no Programme têm uma importância especial, já que isso significa, como já notei, que a qualquer um que planeje fazer a agrégation será exigido se familiarizar com a obra inteira do filósofo. Embora isso tenha mudado em 2005, quando textos específicos (em traduções francesas) foram designados para o exame escrito em vez do corpus inteiro do filósofo, isso afeta a preparação do candidato mais do que as implicações da agrégation que eu estou discutindo agora. Quem, então, aparece mais frequentemente no Programme para o exame escrito? Não surpreendentemente, nos 113 Programmes publicados

37 Jean-Luis Fabiani, professor de sociologia e directeur d'études na École des Hautes Études en Sciences Sociales, que havia sido "preparado" por Derrida para a agrégation de 1974 (Conversa pessoal). 
de 1900 a 2018, ${ }^{38}$ Platão, Aristóteles, Kant e Descartes, todos eles apareceram mais de trinta vezes. Os únicos outros a aparecerem mais que doze vezes foram os estoicos ${ }^{39}$ (26 vezes), Leibniz (25), Spinoza (24) e Hume (21). A única figura do século XVIII ${ }^{40}$ a aparecer mais de dez vezes é Rousseau (12), as únicas figuras do século dezenove a aparecer mais do que cinco vezes são Nietzsche (10; primeira ocorrência em 1970), Hegel (9; primeira ocorrência em 1968) e Comte (6), e as únicas figuras do século XX a aparecer mais de uma vez foram Bergson (7; primeira ocorrência em 1951), Bachelard, Husserl e Russell.

Quando se examinam as aparições totais no Programme, tanto no exame escrito quanto na explicação oral, as quatro presenças filosóficas principais permanecem as mesmas: nos 113 Programmes, Platão aparece 99 vezes, Aristóteles, 84, Kant, 87, e Descartes, 72. Mas esse número total é enganador, porque o número de estudantes que de fato escolhem oferecer uma explicação de um texto em grego é bem inferior àqueles que escolhem explicar um texto em francês. ${ }^{41}$ Quando se leva em consideração que bem mais da metade das ocorrências de Kant e Descartes no Programme estão em francês ou em tradução francesa, ${ }^{42}$ enquanto o aparecimento de Platão e Aristóteles no exame oral são, com apenas duas exceções, sempre da explicação de textos em grego, eu defenderia que a agrégation de fato privilegia os primeiros filósofos em relação aos filósofos

38 Por causa das guerras, nenhum Programme apareceu entre 1915 e 1918, 1941, ou 1945.

39 Além do grupo geral, "Os estoicos" aparecerem para o exame escrito, o Programme frequentemente indica textos ou seleções de Sêneca, Marco Aurélio e Epiteto para a explicação oral.

40 Para fins de análise, estou fazendo uma distinção que reflete a separação, na agrégation, entre "filósofos do século XVIII", como Rousseau ou Diderot, e aqueles filósofos que fazem parte do cânon dos primeiros modernos (de Descartes a Kant), mas que poderiam também, de uma perspectiva estritamente histórica, ser considerados filósofos do século XVIII (por exemplo, Hume ou Kant).

41 Os resultados do exame de 1997 são típicos: 12 candidatos optaram, na explicação de grego, pelo Górgias de Platão (7) ou pelas Eneidas $V$, 8, de Plotino (5), enquanto quase quatorze vezes mais (162) optaram pela explicação em francês da uma seleção de Leibniz (Discours de métaphysique, 42), Rousseau (Emile, Livro 4, 35), Maine de Biran (Mémoires sur la décomposition de la pensée, 43), ou Bergson (Matière et mémoire, 42).

4233 dos 55 aparecimentos de Kant no Programme do exame oral são em traduções francesas e 33 dos 42 aparecimentos de Descartes são também em francês (as outras são em latim).

Cad. Nietzsche, Guarulhos/Porto Seguro, v.41, n.2, p. 117-144, maio/agosto, 2020.| 135 
Schrift, A. D.

antigos, ${ }^{43}$ com Kant sendo o filósofo que aparece mais frequentemente (aparecendo 65 vezes no Programme do exame escrito ou do oral em francês), com Descartes logo em segundo (63), e ambos aparecem em bem mais que metade dos Programmes. De fato, reconhecendo a importância de aparecer como escolha da explicação em francês, Leibniz (53) chega a exceder Platão no número de ocorrências, e Malebranche (41) e Rousseau (39) quase se equiparam em número de ocorrências.

V

Como fica claro por esses números, o Programme e a agrégation sempre foi pesadamente direcionado para os filósofos canônicos, dos primeiros modernos e dos gregos. De fato, dos 406 filósofos indicados (individualmente ou coletivamente) para o Programme impresso desde 1900, 83\% (337) deles eram antigos (154) ou primeiros filósofos modernos (183). Isso vai além dos quatro mais frequentemente representados no Programme - Kant, Descartes, Platão e Aristóteles - como Leibniz, Spinoza, Hume e representantes do estoicismo, aparecendo todos estes em quase metade dos Programmes desde 1900.

Tendo mostrado a influência da agrégation de philosophie em geral, deixe-me retornar a Nietzsche e argumentar que o terceiro momento nietzschiano na França - momento filosófico de Nietzsche - começou em 1958, quando La Généalogie de la Morale apareceu na lista de leitura em francês traduzida para a agrégation de philosophie. Aparecendo novamente em 1959, essas foram as primeiras ocorrências de Nietzsche no Programme desde o seu único aparecimento anterior, quando Die Genealogie der Moral (sic) foi listada como uma opção para a explicação oral de alemão em 1929, e a essas ocorrências em 1958 e 1959 se seguiu uma série de aparecimentos de Nietzsche no Programmes, que continuaria nas próximas duas

43 Pela óbvia razão de que o francês era, é claro, a língua materna da grande maioria dos candidatos. 
décadas. ${ }^{44}$ Precisamente nesses anos, quando a Genealogia foi um dos textos solicitados (1958-59), Gilles Deleuze estava começando sua carreira universitária na Sorbonne e ofereceu um curso sobre a Genealogia da moral no inverno de $1958,{ }^{45}$ o que certamente explica por que a Genealogia desempenha um papel central no Nietzsche et la philosophie de Deleuze. Para avaliar a novidade do momento filosófico de Nietzsche, considere o seguinte: em 1959, Jean Wahl ministrou o primeiro curso de palestras dedicado exclusivamente a Nietzsche oferecido por um professor de filosofia na Sorbonne: $L a$ Pensée philosophique de Nietzsche des années 1885-1888. E Wahl ofereceu a segundo curso, em 1961, sobre L'Avant-dernière pensée de Nietzsche. E entre 1958 e 1962, vemos aparecer os primeiros seis artigos sobre Nietzsche publicados em revistas francesas prestigiosas, com artigos de Hermann Wein, Pierre Klossowski, Angèle Kremer-Marietti, Jean Wahl e Henri Birault aparecendo na Revue de métaphysique et de morale, e Pierre Fruchon publicando o primeiro artigo sobre Nietzsche a aparecer nos Études philosophiques. ${ }^{46}$ Para considerar como extraordinárias foram essas publicações sobre Nietzsche, deixe-me mencionar dois outros fatos para contextualizar essas publicações. Primeiro, que, antes de 1958, o último artigo sobre Nietzsche publicado na Revue de métaphysique et de morale foi uma resenha do estudo de seis volumes de Charles Andler, publicada em duas partes, em 1931 e $1932 .{ }^{47} \mathrm{E}$, segundo, Jean Wahl começou sua resenha, de 1963, do Nietzsche et la philosophie de Deleuze na

\footnotetext{
44 Also sprach Zarathustra apareceu como opção em alemão em 1962 e 1963, e Nietzsche foi listado para o exame escrito em 1970 e 1971, e novamente em 1976 e 1977.

45 Agradeço a Giuseppi Bianco por me providenciar uma cópia das anotações de um estudante do curso de Deleuze de 1958 que oferecia um "Commentaire de 'La Généalogie de la morale”.

46 Hermann Wein, "Métaphysique et anti-métaphysique: Accompagné de quelques réflexions pour la défense de l'oeuvre de Nietzsche" (1958), Pierre Klossowski, "Nietzsche, le polythéisme et la parodie” (1958), Angèle Kremer-Marietti, "Nietzsche et quelques-uns de ses interprètes actuels" (1959), Jean Wahl, "Le Problème du temps chez Nietzsche" (1961) e Henri Birault, "En quoi, nous aussi, nous sommes encore pieux" (1962), apareceram na Revue de métaphysique et de morale, enquanto "Note sur l'idée de création dans la dernier pensée de Nietzsche" (1962), de Pierre Fruchon, apareceu em Études philosophiques.
}

47 Marie-Anne Cochet, "Nietzsche d'après son plus récent interprète." 
Revue de métaphysique et de morale afirmando que o livro de Deleuze ombreava os mais importantes livros sobre Nietzsche: esses seriam os de Jaspers, Heidegger, Fink e Lou Salomé. ${ }^{48}$ Não ter citado nenhum filósofo francês não é descuido; em vez disso, isso reflete quão pouca pesquisa sobre Nietzsche era feita por filósofos na França antes de 1962. De fato, antes do livro de Deleuze, haviam sido publicados apenas seis livros sobre Nietzsche por filósofos na França, e desses, apenas três tinham sido publicados desde 1902. ${ }^{49}$

Junto com o aparecimento de Nietzsche na agrégation, a publicação do livro de Deleuze e a publicação em alemão do Nietzsche de Heidegger em dois volumes, em 1961, ${ }^{50}$ o momento filosófico francês de Nietzsche é marcada por dois congressos. Assim falava Zaratustra apareceu como opção para a explicação de alemão na agrégation, em 1962 e 1963, e no ano seguinte um congresso se realizou no Abbey at Royaumont, de 4 a 8 julho em 1964, que desempenhou um papel significativo na legitimação da reputação filosófica de Nietzsche na França. ${ }^{51}$ Organizado por Deleuze e presidido pelo famoso historiador da filosofia Martial Guéroult, além de apresentações de jovens filósofos como Deleuze, Foucault e Gianni Vattimo, escritores de vanguarda, como Pierre Klossowski, houve apresentações feitas por filósofos famosos e estabelecidos, como Jean Wahl, Jean Beaufret, Karl Löwith, Eugen Fink e Henri Birault, o prestigioso filósofo não-acadêmico Gabriel Marcel, e Giorgio Colli e Mazzino Montinari, os editores italianos que estavam começando

48 Wahl, 1963, pp. 352-79; 352.

49 Três desses foram publicados em 1902: Eugène de Roberty, Frédéric Nietzsche: Contribution à l'histoire des idées philosophiques et sociales à la fin du XIXe siècle (Paris: F. Alcan); Pierre Lasserre, La morale de Nietzsche (Paris: Mercure de France); e Alfred Fouillée, Nietzsche et l'immoralisme (Paris: F. Alcan). Dos outros três, dois eram textos introdutórios: Félicien Challaye, Nietzsche (Paris: Mellottée, 1933); e André Cresson, Nietzsche, sa vie, son oeuvre, avec un exposé de sa philosophie et des extraits de ses oeuvres (Paris: Presses Universitaires de France, 1942). 0 ultimo texto anteiror ao de Deleuze foi Thèmes et structures dans l'œeuvre de Nietzsche, de Angèle Kremer-Marietti, (Paris: Lettres modernes, 1957).

50 O Nietzsche de Heidegger não foi traduzido para o francês até 1971, em dois volumes, traduzido por Pierre Klossowski e publicado pela Gallimard.

51 Os anais foram publicados como Nietzsche. Cahiers de Royaumont, Philosophie VIIe colloque, 4-8 Juillet 1964 (Paris: Éditions de Minuit, 1967).

138 | Cad. Nietzsche, Guarulhos/Porto Seguro, v.41, n.2, p. 117-144, maio/agosto, 2020. 
seu trabalho numa nova edição crítica das obras de Nietzsche..$^{52} \mathrm{Em}$ sua própria apresentação, como era comum para o organizador do congresso, Deleuze fez um discurso de encerramento em que ele apresentou um panorama das apresentações dos dias anteriores. ${ }^{53}$ Ele observou cinco temas que foram discutidos na apresentações e nas discussões. As máscaras de Nietzsche e a necessidade de interpretação; a vontade de potência como aquilo que permanece atrás das máscaras; relações de afirmação e negação; a afirmação dionisíaca no eterno retorno; e as relações de Nietzsche com outros pensadores (incluindo Dostoiesvski, Hesse, Marx e Freud, entre outros). O que Deleuze não pôde dizer, mas que se tornará claro logo depois, foi que o Congresso de Royaumont marcou a confirmação da reputação filosófica de Nietzsche na França ao entrar no cânon filosófico, um evento afirmado pelo fato de que seu nome fez seu primeiro aparecimento no exame escrito da agrégation de philosophie em 1970, reaparecendo mais três vezes no exame escrito nos anos seguintes.

Enquanto o Congresso de Royaumont afirmou o lugar de Nietzsche no cânon, um segundo grande congresso, de dez dias, em Cerisy-la-Salle, em julho de $1972,{ }^{54}$ colocou Nietzsche no centro da filosofia francesa contemporânea. E enquanto o Congresso de Royaumont pode se relacionar apenas tangencialmente com o fato de o Zarathustra de Nietzsche ter aparecido na explicação em alemão dois anos antes, o Congresso de Cerisy reflete uma atenção generalizada para com as obras de Nietzsche, resultante de seu aparecimento nos programas escritos da agrégation de philosophie de 1970 e 1971.

52 A edição original de Colli e Montinari era para aparecer em italiano, pela Adelphi Edizioni, e em francês, pela Gallimard, editada por Foucault e Deleuze. Montinari tinha tentado, sem sucesso, desde 1961, conseguir um editor alemão que concordasse em publicar uma edição em alemão; conversas no Congresso de Royaumont entre Montinari e Karl Löwith levaram Löwith a interceder e persuadir a Walter de Gruyter a adquirir os direitos da Adelphi e da Gallimard para publicar a edição Colli-Montinari em sua língua original. Discuto isso numa história da tradução em inglês da edição crítica, que estou no momento editando pela Stanford University Press, em Schrift, 2007.

53 Ver: Deleuze, 2002, pp. 163-77.

54 Mais de 800 páginas com as apresentações e as discussões que se seguiram desse congresso foram publicadas em dois volumes como Nietzsche aujourd'hui (Paris: Union Générale d'Éditions, 1973). 
Com o título Nietzsche aujourd'hui, o Congresso de Cerisy incluiu apresentações de muitos dos participantes que também falaram no Congresso de Royaumont (incluindo Deleuze, Klossowski, Löwith e Fink). Além da apresentação por pesquisadores associados com a obra de Nietzsche, como Eugen Biser, Eric Blondel, Pierre Boudot, Richard Roos e Paul Valadier, ele inclui também uma apresentação significativa de Jacques Derrida, "La Question du style," que seria depois revisada e publicada como Éperons: Les Styles de Nietzsche, assim como apresentações de um número de pesquisadores associados a Derrida, incluindo Sarah Kofman, Philippe Lacoue-Labarthe, Jean-Luc Nancy, Bernard Pautrat e Jean-Michel Rey. Contudo, para ressaltar outra correlação entre Nietzsche e a agrégation, muitos desses filósofos pós-estruturalistas participaram de um seminário aberto de Derrida na École Normale Supérieure, no inverno de 1970, sobre a "Théorie du discours philosophique: La métaphore dans le texte philosophique," que reflete não só a indicação de Nietzsche para a dissertação sobre a história da filosofia, mas também o fato de "Le langage" ter sido o tema do segundo ensaio escrito. ${ }^{55}$

Para pesquisadores anglófonos de minha geração, nossa introdução ao chamado Nietzsche francês veio via a antologia inovadora, publicada pela primeira vez em 1977 com o título The New Nietzsche. Embora na antologia de Allison também incluísse seleções de Heidegger, dos pesquisadores norte-americanos Alphonso Lingis e Thomas J. J. Altizer, sua importância histórica deve ser posta na sua introdução, a estudantes de filosofia falantes do inglês, das interpretações de Nietzsche nas obras Klossowski, Deleuze, Derrida, Sarah Kofman e outros. E enquanto Allison chamou de "novo Nietzsche," eu defenderia que, no contexto francês, ele poderia se

\footnotetext{
55 Entre os que assistiam ao seminário de Derrida, estavam Bernard Pautrat e Sarah Kofman, que reconhecem que os rascunhos de seus livros sobre Nietzsche - Versions du soleil. Figures et système de Nietzsche e Nietzsche et la métaphore - foram escritos e apresentados durante esse seminário. As contribuições do próprio Derrida para o seminário formam a base de seu ensaio "La Mythologie blanche: La métaphore dans le texte philosophique", publicado iniciamente em Poétique 5 (1971):1-52, e republicado em Marges de la philosophie (Paris: Éditions du Minuit, 1972), pp. 247-324.
}

140 | Cad. Nietzsche, Guarulhos/Porto Seguro, v.41, n.2, p. 117-144, maio/agosto, 2020. 
A Agrégation de Philosophie e a emergência do nietzschianismo...

chamar "o Nietzsche dos filósofos", já que ele oferece mais evidências da influência da agrégation.

Quando se observam os agradecimentos na antologia de Allison, descobre-se que os ensaios de Michel Haar, Eric Blondel e Jean Granier foram todos publicados em 1971, enquanto o capítulo de Kofman veio do seu livro de 1972, Nietzsche et la métaphore. Além disso, tanto o capítulo de Deleuze quanto o ensaio de Derrida foram traduções de suas apresentações no Congresso de Cerisy de 1972. Em outras palavras, dos dez capítulos da antologia de Allison escritos por acadêmicos franceses, no mínimo seis foram escritos nos dois anos seguintes ao aparecimento no Programme, em 1970, e um sétimo, de Paul Valadier, veio de um livro publicado dois anos depois. Olhando de forma mais ampla para a pesquisa francesa nos anos posteriores às quatro ocorrências de Nietzsche na aggregation, nos anos 1970, a influência é ainda mais óbvia: de 1970 a 1980, a bibliografia de Nietzsche em Weimar lista mais que 275 livros ou artigos franceses escritos primariamente por filósofos. Esse número não inclui traduções das próprias obras de Nietzsche ou resenhas de outras pesquisas sobre Nietzsche, que eram muitas. Em comparação, de 1920 a 1957, 334 obras francesas estão listadas nessa bibliografia, a maioria traduções de obras já publicadas na França ou escritas por germanistas ou ensaístas de vanguarda, como Gide ou Bataille. ${ }^{56}$

Contudo, o terceiro momento de Nietzsche pode ter passado, já que seus aparecimentos na agrégation diminuíram significativamente nas últimas quatro décadas. Desde 1977, ele apareceu apenas oito vezes no Programme para o exame escrito, aproximadamente uma vez por década - em 1988 e 1989, em 1998 e 99, e 2006 e 2007 - duas vezes com Jenseits von Gut und Böse para a explicação de alemão, em 1993 e 1994. Assim, Nietzsche não ter aparecido de forma alguma desde 2007 pode ser motivo de preocupação para aqueles

56 Esta informação pode ser encontrada na Nietzsche-Bibliographie na Stiftung Weimarer Klassik und Kunstsammlungen. Ver: http://ora-web.swkk.de:7777/swk-db/niebiblio/index.html. 
Schrift, A. D.

entre nós associados ao Nietzsche filosófico francês e seu lugar na filosofia francesa de forma geral. Mas, para concluir com uma nota otimista, Nietzsche aparece no Programme para o exame escrito da aggregation em 2020, a primeira vez em treze anos.

\title{
The Agrégation de Philosophie and the Emergence of French Philosophical Nietzscheanism
}

\begin{abstract}
While it is widely believed that the French attention to Nietzsche in the 1960s was a response to the publication of Heidegger's Nietzsche lectures in 1961, I argue that the appearance of Nietzsche on the examination reading list for the agrégation de philosophie provides the best explanation for the emergence of the socalled "New Nietzsche" associated with French poststructuralism. Following a brief explanation of how the agrégation functions within French academic culture, and the influence it has on both the teaching and publishing activities of the professoriate, I analyze the rise in interest in Nietzsche's work among philosophers beginning in the late 1950 s as a consequence of this examination.
\end{abstract}

Keywords: Nietzsche, agrégation de philosophie, poststructuralism, French academic culture, Deleuze, Bataille, Henri Lefebvre.

\section{Referências}

ANDLER, Charles. La Dernière philosophie de Nietzsche: Le Renouvellement de toutes les valeurs. Paris: Bossard, 1931.

. La Jeunesse de Nietzsche: Jusqu'à la rupture avec Bayreuth. Paris: Bossard, 1921.

. La Maturité de Nietzsche: Jusqu’à sa mort. Paris: Bossard, 1928.

. Le Pessimisme esthétique de Nietzsche: Sa philosophie à l'époque wagnérienne.Paris: Bossard, 1921.

. Les Précurseurs de Nietzsche. Paris: Bossard, 1920. 
A Agrégation de Philosophie e a emergência do nietzschianismo...

. Nietzsche et le transformisme intellectualiste: La Philosophie de sa période française. Paris: Bossard, 1922.

. Nietzsche, sa vie et sa pensée. Paris: Gallimard, 1958.

ARON, Raymond. Memoirs: Fifty Years of Political Reflection. Tradução: George Holoch. New York: Holmes and Meier, 1990, p. 25.

BATAILLE, Georges. "Nietzschean Chronicle". In: Visions of Excess: Selected Writings, 1927-1939. Ed. e Trad. Allan Stoekl. Minneapolis: University of Minnesota Press, 1985.

. Sur Nietzsche: Volonté de chance. Paris: Editions Gallimard, 1945.

CANIVEZ, André. "Le Jury d'agrégation: Le cas de Charles Andler". Corpus, revue de philosophie, 24/25 (1994), pp. 199-200.

CHERVEL, André. Histoire de l'agrégation: Contribution à l'histoire de la culture scolaire. Paris: Éditions Kimé, 1993.

DELEUZE, Gilles. "Conclusions: Sur la volonté de puissance et l'éternal retour," in Nietzsche. Cahiers de Royaumont, pp. 275-87.

DERRIDA, Jacques. Éperons: Les styles de Nietzsche. Paris: Flammarion, 1978. . "La Mythologie blanche: La métaphore dans le texte philosophique". In: Marges de la philosophie. Paris: Éditions du Minuit, 1972.

. La Vérité en peinture. Paris: Flammarion, 1978.

FABIANI, Jean-Louis. "Enjeux et usages de la 'crise' dans la philosophie universitaire en France au tournant du siècle". Annales ESC (mars-avril 1985), pp. 377-409.

FORTH, Christopher E. Zarathustra in Paris: The Nietzsche Vogue in France 1891-1918. DeKalb: Northern Illinois University Press, 2001.

FOUILLÉE, Alfred. Nietzsche et l'immoralisme. Paris: Félix Alcan, 1902.

KOFMAN, Sarah. Nietzsche et la métaphore. Paris: Payot, 1972.

KREMER-MARIETTI, Angèle. Thèmes et structures dans l'œuvre de Nietzsche. Paris: Lettres modernes, 1957. 
Schrift, A. D.

Le RIDER, Nietzsche en France de la fin du XIXe siècle au temps present. Paris: Presses Universitaires de France, 1999, p. 104.

LEFEBVRE, Henri. Nietzsche. Paris: Éditions Sociales Internationales, 1939.

LICHTENBERGER, Henri. La Philosophie de Nietzsche. Paris: Alcan, 1898.

Nietzsche aujourd'hui. Paris: Union Générale d'Éditions, 1973.

PAUTRAT, Bernard. Versions du soleil. Figures et système de Nietzsche. Paris: Éditions du Seuil, 1971.

PINTO, Louis. Les Neveux de Zarathoustra. Paris: Éditions du Seuil, 1998.

SARTRE, Jean-Paul. Euvres romanesques. Paris: Éditions Gallimard, 1981, p. xlv.

SCHRIFT, Alan D. "French Nietzscheanism". In: Schrift, Alan. D. Poststructuralism and Critical Theory's Second Generation. The History of Continental Philosophy V. 6. London: Acumen Press/Chicago: University of Chicago Press, 2010.

" "Translating the Colli-Montinari Kritische Studienausgabe". In: The Journal of Nietzsche Studies 33 (2007), pp. 64-72.

TONNELAT, Ernst. Charles Andler, sa vie et son oeuvre. Paris: Les Belles-lettres, 1937.

VERBAERE, Laure. La Réception français de Nietzsche 1890-1910. Thèse de doctorat d'histoire, Université de Nantes, 1999.

VIRTANEN, Reino. "Nietzsche and the Action Française: Nietzsche's Significance for French Rightist Thought," Journal of the History of Ideas 11, April 1950.

WAHL, Jean. "Nietzsche et la philosophie”. Revue de Métaphysique et de Morale, 68, 3. Juillet-Septembre 1963, pp. 352-79.

Enviado: 05/03/2020

Aceito: 05/04/2020

144 | Cad. Nietzsche, Guarulhos/Porto Seguro, v.41, n.2, p. 117-144, maio/agosto, 2020. 